Research Article

\title{
Field Investigation of Blasting-Induced Vibration in Concrete Linings during Expansion of Old Highway Tunnel
}

\author{
Ya-Qiong Wang $\left(D,{ }^{1}\right.$ Lin-Jin Gong, ${ }^{2}$ Nan-Nan An, ${ }^{2}$ Xing-Bin Peng, ${ }^{2}$ Wei Wang, ${ }^{1,3}$ \\ and Zhi-Feng Wang (D) \\ ${ }^{1}$ School of Highway, Chang'an University and Shaanxi Provincial Major Laboratory for Highway Bridge \& Tunnel, \\ Xi'an 710064, China \\ ${ }^{2}$ School of Highway, Chang'an University, Xi'an 710064, China \\ ${ }^{3}$ CCCC Second Harbour Engineering Co., Ltd., Wuhan, Hubei 430040, China
}

Correspondence should be addressed to Zhi-Feng Wang; zhifeng.wang@chd.edu.cn

Received 23 June 2020; Revised 6 August 2020; Accepted 30 January 2021; Published 10 February 2021

Academic Editor: Hugo Rodrigues

Copyright (c) 2021 Ya-Qiong Wang et al. This is an open access article distributed under the Creative Commons Attribution License, which permits unrestricted use, distribution, and reproduction in any medium, provided the original work is properly cited.

\begin{abstract}
Numerous mountain highway tunnels in China do not satisfy the current traffic design standards and therefore need to be rebuilt or expanded. The drilling-blasting method is the primary method employed in China for expanding mountain highway tunnels, and it is crucial to monitor the vibrations caused by blasting. This study conducted a field investigation of the vibrations caused by blasting during the expansion of Yujiaya tunnel, which was built in 1999. The blasting-induced vibrations in the new and old concrete linings were monitored and analyzed during the expansion. The measured values of the peak particle velocity (PPV) varied within the range of $0.097-8.246 \mathrm{~cm} / \mathrm{s}$. The attenuation law of the PPV was determined via a regression analysis using Sadovsky's empirical formula. The relationship between the main vibration frequency and the distance from the blasting source was expressed as a power function. Finally, the safety distances of the concrete linings subject to blasting vibrations were analyzed and discussed.
\end{abstract}

\section{Introduction}

In China, numerous old mountain highway tunnels have undergone local collapse, water leakage, and lining cracking, among other issues [1-5]. These highway tunnels are in a subhealth state, have entered the "high maintenance" management period, and do not satisfy current traffic design standards; thus, they must be rebuilt or expanded [6]. The drilling-blasting method is the primary method employed in China for the construction of mountain tunnels [7-9], where blasting control is the key issue faced during the process of expanding old tunnels [10-13]. During tunnel expansion and the construction processes involved, blasting vibrations of different strengths inevitably cause macroscopic damage or microscopic cumulative damage to underground structures or adjacent buildings [14-18]. If the blasting control is not reasonable, it may cause a continuous collapse of the old concrete lining, introducing considerable difficulty to the expansion of tunnels [19-22]. Therefore, it is important to monitor blasting-induced vibration during the process of expanding old tunnels for ensuring safety [23-26]. Several studies have investigated the effects of underground engineering blasting on adjacent structures (in terms of the critical limit, dynamic response caused by blasting, etc.) via field tests, numerical simulations, and model tests [27-31]; however, most of them focused on the linings of existing tunnels, adjacent buildings, airport runways, and hydropower stations [32-36]. In the case of a wireless sensor network, Lai et al. [37] investigated the effects of blastinduced vibrations on the structure of the existing tunnel. Feldgun et al. [14] proposed a comprehensive approach to simulate an explosion occurring inside a buried axisymmetric lined cavity. However, there have been few studies on the effects of blasting vibrations caused by in situ expansion of highway tunnels, which require close attention. 
This study aimed to perform a field test to investigate the vibrations caused by blasting during the in situ expansion of the Yujiaya tunnel, which was built in 1999; it is the first in situ expansion project conducted in the Shaanxi Province. In this study, the vibration velocity and the main vibration frequency in the new and old concrete linings were measured. The attenuation law of the peak particle velocity (PPV) for the new and old concrete linings was analyzed. The relationship between the main vibration frequency and the distance to the blasting source was examined. Additionally, the safety distances of concrete linings subject to blasting vibrations were investigated.

\section{Project Background}

Yujiaya tunnel is a single-hole tunnel located on the S309 line of the highway from Lueyang County to Kang County, Shaanxi province, as shown in Figure 1. After complete construction, it was opened to traffic on June 15,1999 . On July 14, 2015, because the top lining concrete of the tunnel partially collapsed, the tunnel was analyzed and tested in detail to verify its quality status. As shown in Figure 2, the test results indicated that Yujiaya tunnel had the following damage: a partial collapse of the lining, cracks in the lining and water leakage, an insufficient lining thickness and defects, an insufficient lining strength, drainage system failure, no lighting, no fire protection, safety facilities, and so forth. Figure 3 presents cross-sectional views of the Yujiaya tunnel before and after expansion. As shown, the height and width of the old Yujiaya tunnel were 7.8 and $8.5 \mathrm{~m}$, respectively. To improve the traffic conditions, they were increased to 8.75 and $10.0 \mathrm{~m}$, respectively, in the new Yujiaya tunnel. Figure 4 presents a longitudinal view of the Yujiaya tunnel and the geological conditions. As shown, the Yujiaya tunnel was approximately $518 \mathrm{~m}$ long (medium-long tunnel) with mileage piles of $\mathrm{K} 101+850-\mathrm{K} 102+368$. The geological conditions for the Yujiaya tunnel are also presented in Figure 4. As shown, the strata in the tunnel area were mainly composed of phyllite rock, and the Yujiaya tunnel crossed three fault fracture zones and limestone strata. The unconfined compressive strength of the phyllite rock ranged from 12.8 to $39.6 \mathrm{MPa}$.

The in situ expansion process of the tunnel is mainly divided into two phases: demolition of the old lining structure and excavation of local surrounding rock. The old lining is demolished mainly via the cutting method along with low-magnitude vibration and loose, weak blasting. Moreover, the excavation of the surrounding rock is mainly conducted via weak blasting, and mechanical machines can be used for this process. In the in situ expansion, two and three rows of boreholes are arranged around the rock in the upper and lower steps, respectively, which are perimeter holes and auxiliary holes from the outside to the inside, as shown in Figure 5. The perimeter holes are spaced and uncoupled charge structures, whereas the auxiliary holes are continuous uncoupled charge structures. A slight delay in blasting is applied between each row of holes (different-colored holes use different detonator segments). The detonator segments correspond to $\overline{1}, \overline{2}$, and $\overline{5}$, and the delay between adjacent detonator segments is $100 \mathrm{~ms}$ (determined according to the blasting engineer's experience). Thus, layer-by-layer detonation is performed from the adjacent free face to the outside, eliminating the stress wave superposition effect caused by the explosion.

\section{Field Monitoring Program}

3.1. Monitoring Principle Using TC-4850. The blasting vibration testing system was primarily composed of a signal sensor (picker) and a data recorder. A three-vector vibration sensor and a TC-4850 self-recording instrument (Chengdu Zhongke Instrument Co., Ltd.) were used during the monitoring process. The sensor converted the blasting vibration signals to electrical signals, which were then converted to digital signals through analog-to-digital conversion via the self-recording instrument. Finally, the data recorder was connected to the computer through a special data line after the test, and the vibration signals were extracted, stored, processed, and analyzed using the Blasting Vibration Analysis software [38]. The test process is depicted in Figure 6. In the field test, the PPV and main vibration frequency were monitored. The PPV and the main vibration frequency were in the ranges of $0-35 \mathrm{~cm} / \mathrm{s}$ and $0-10 \mathrm{kHz}$, respectively, and their test accuracies were $0.0001 \mathrm{~cm} / \mathrm{s}$ and $0.1 \mathrm{~Hz}$, respectively.

3.2. Monitoring Scheme and Layout of Test Points. The layout of the monitoring points adhered to the following principles: (1) the location and direction monitoring of the maximum PPV; (2) real-time monitoring of the blasting vibrations; and (3) observation of the attenuation law of the blasting vibrations. According to the foregoing monitoring principles and the propagation law of blast stress waves, the monitoring sections were arranged on both sidewalls of the new and old sections of the Yujiaya tunnel. Two monitoring points were set in each section. The monitoring points were determined to be at the same height as that of the side walls: approximately $1.5 \mathrm{~m}$ above road level, at which it was convenient to perform measurements. As shown in Figure 7, four monitoring points were arranged for each blasting process denoted as $C 1, C 2, C 3$, and $C 4$.

The distances between the monitoring points on each side and the blasting source were $R_{1}, R_{2}, R_{3}$, and $R_{4}$. A threevector sensor was installed at each monitoring point to measure three vibration velocities: the horizontal radial velocity $V_{\mathrm{X}}$, horizontal tangential velocity $V_{\mathrm{Y}}$, and vertical velocity $V_{\mathrm{Z}}$. Because the terrain at each monitoring point was relatively flat and the height difference between adjacent monitoring points was small, the influence of the height difference on the propagation of the blasting stress wave could be neglected in the field test.

\section{Results and Discussion}

4.1. $P P V$. In the field test, the vibration velocities in different directions were measured. Figure 8 presents typical curves of the measured vibration velocities $\left(V_{X}, V_{Y}\right.$, and $\left.V_{Z}\right)$ in the 


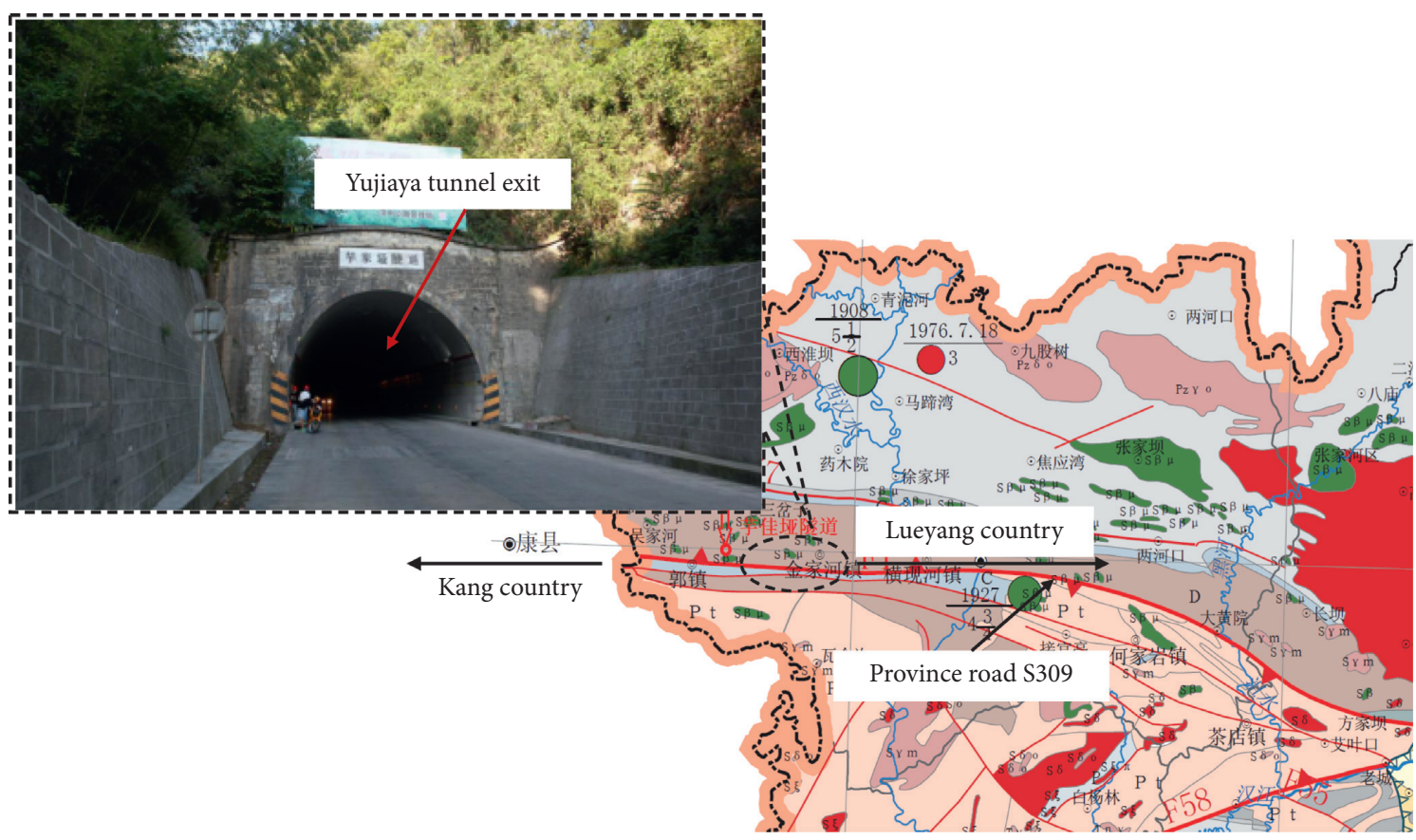

Figure 1: Plan view of the location of Yujiaya tunnel.

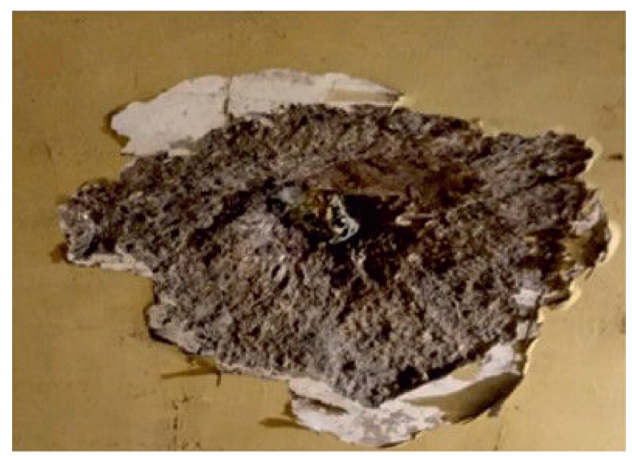

(a)

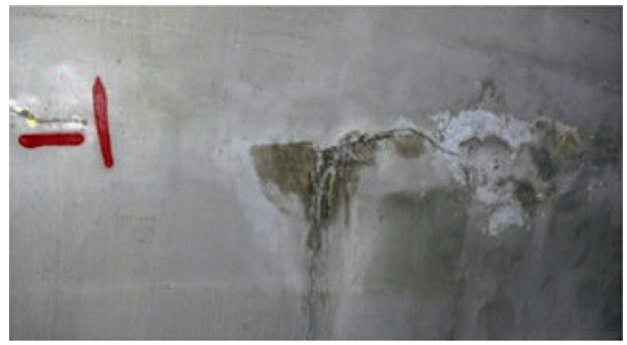

(c)

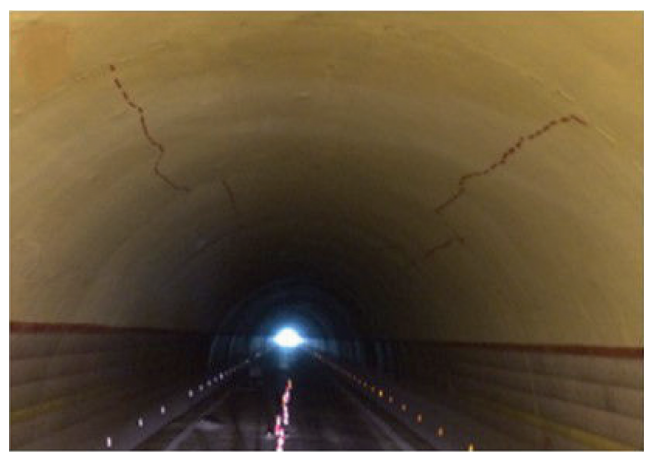

(b)

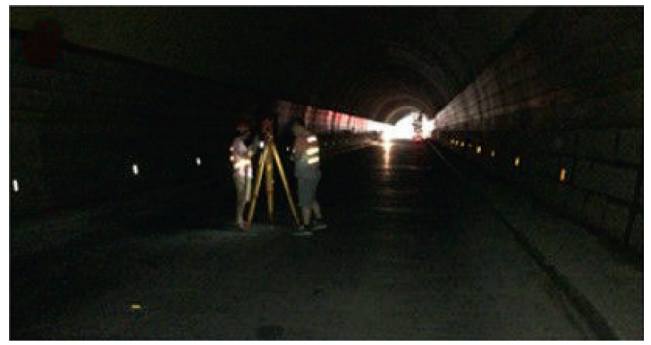

(d)

Figure 2: Damage to Yujiaya tunnel: (a) partial collapse of the lining; (b) cracks in the lining; (c) leakage; (d) poor traffic conditions.

new concrete lining for one test. As shown, the peak vibration velocities (PPVs) in the three directions were 0.197 , 0.280 , and $0.384 \mathrm{~cm} / \mathrm{s}$, respectively. To further study the attenuation law of the peak vibration velocities caused by blasting in the expansion of the Yujiaya tunnel, 10 field tests were conducted during the construction process, and a large amount of PPV data was collected, as shown in Table 1. Many researchers have proposed prediction formulas for blasting vibration, which are generally based on Sadovsky's empirical formula, and the parameters are revised and perfected in actual blasting engineering. Additionally, formulas for predicting the relationship among the PPV, trinitrotoluene (TNT) weight, and safe distance were also proposed in China and were incorporated into the Safety regulations for blasting in China [39]. The PPV can be predicted as follows: 


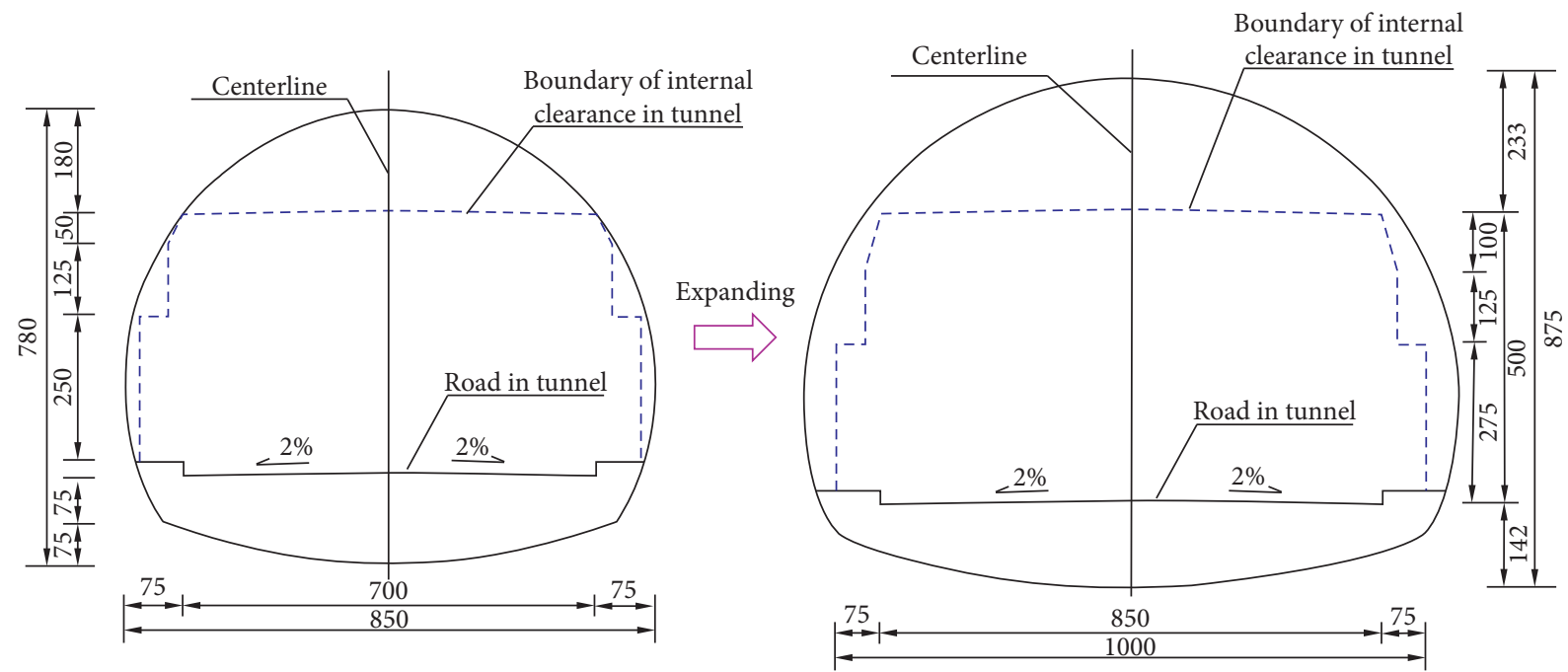

Figure 3: Cross-sectional views of Yujiaya tunnel before and after expansion.

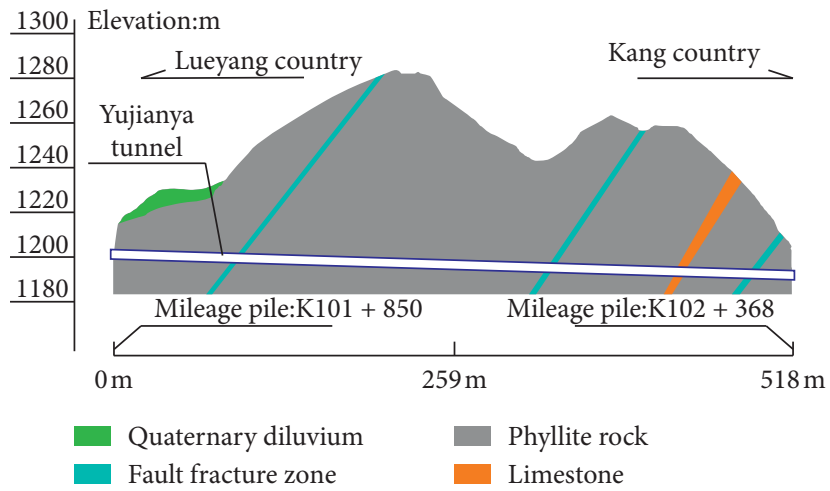

FIgURE 4: Longitudinal view of Yujiaya tunnel and the geological conditions.

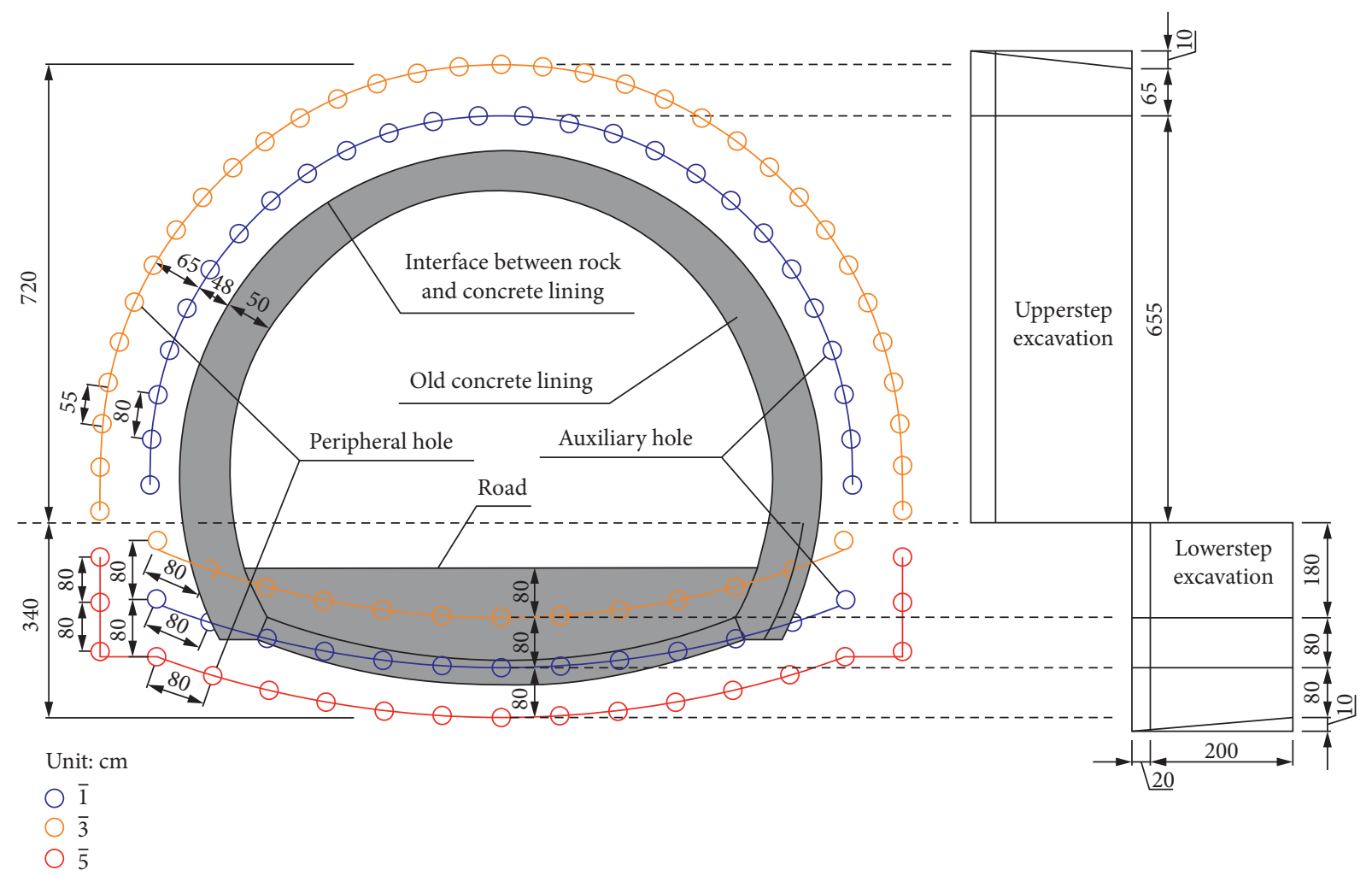

FIgURE 5: Layout of blasting holes during the construction for expanding Yujiaya tunnel. 




Figure 6: Principle for testing the blasting-induced vibrations.

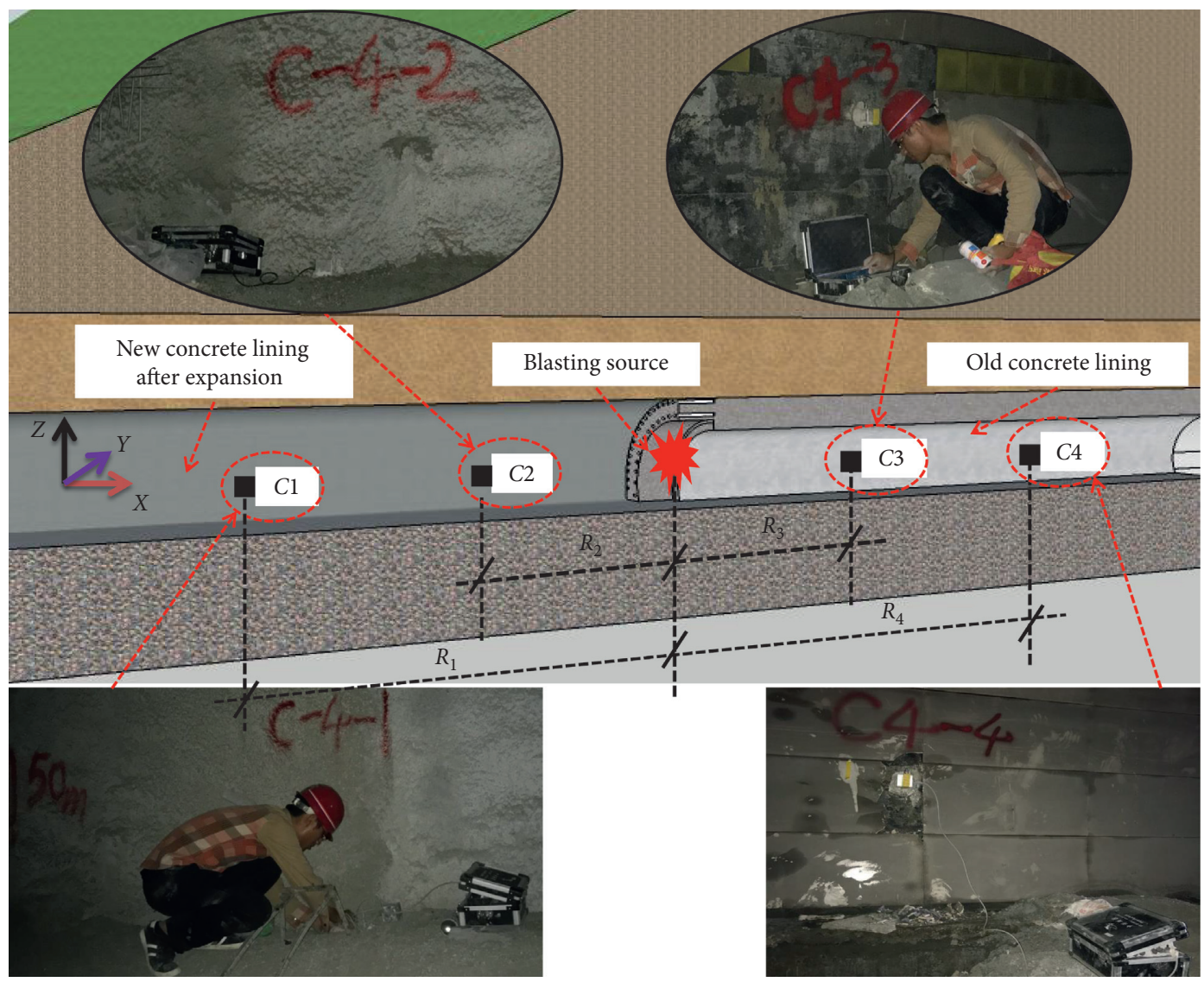

FIgURe 7: Layout of the monitoring points in the tunnel lining.

$$
\begin{aligned}
& \mathrm{PPV}=K\left(\frac{\mathrm{Q}^{1 / 3}}{R}\right)^{\alpha}=K[\mathrm{PD}]^{-\alpha}, \\
& {[\mathrm{PD}]=\left(\frac{R}{Q^{1 / 3}}\right),}
\end{aligned}
$$

where PPV represents the PPV (in $\mathrm{cm} / \mathrm{s}$ ); $Q$ represents the TNT weight $(\mathrm{kg}) ; R$ represents the linear distance from the blasting source to monitoring points (m); $K$ and $\alpha$ are parameters related to the blasting vibrations, which are influenced by the rock characteristics, site conditions, blasting methods, and so forth; and [PD] represents the proportional distance $\left(\mathrm{m} / \mathrm{kg}^{1 / 3}\right)$. 

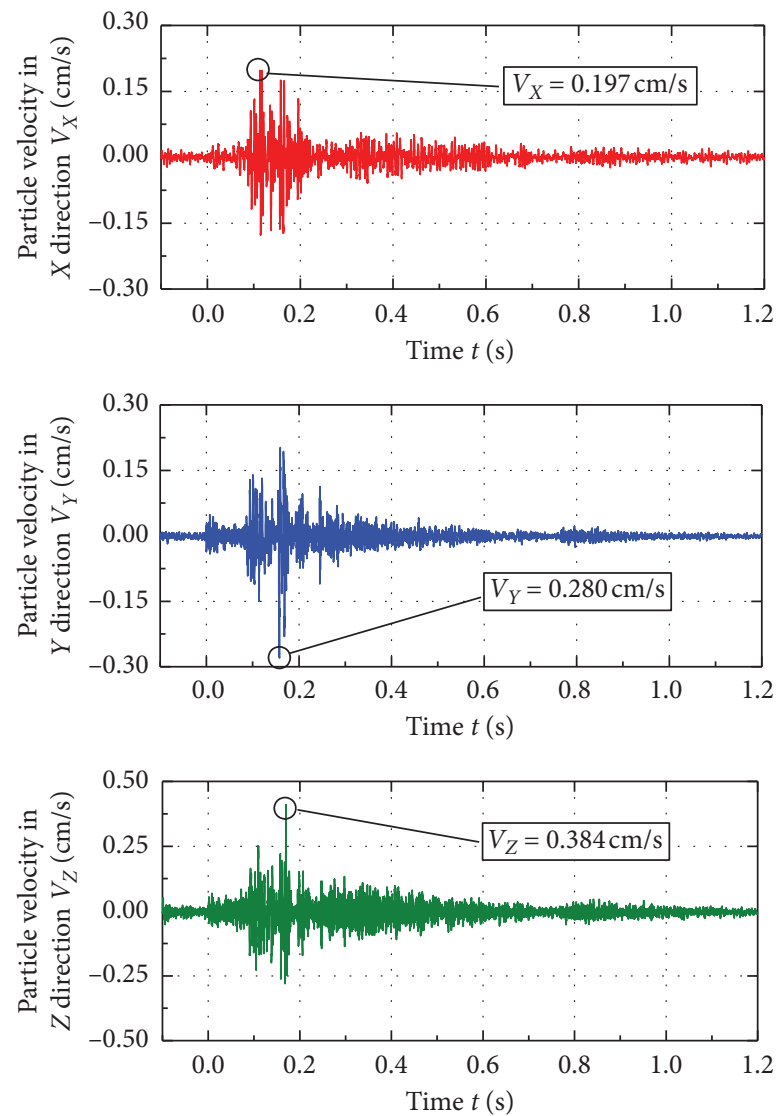

Figure 8: Typical curve of measured vibration velocities $\left(V_{X}, V_{Y}\right.$, and $\left.V_{Z}\right)$ for the new concrete lining (in test $1, R_{4}=110.8$ ).

TABLe 1: Measured PPVs in this case history.

\begin{tabular}{|c|c|c|c|c|c|c|c|c|c|}
\hline \multirow{2}{*}{$\begin{array}{l}\text { Test } \\
\text { number }\end{array}$} & \multirow{2}{*}{$\begin{array}{l}\text { TNT weight } \\
\text { per delay }(\mathrm{kg})\end{array}$} & \multirow{2}{*}{$\begin{array}{l}\text { Distance to blasting } \\
\text { source }(\mathrm{m})\end{array}$} & \multicolumn{3}{|c|}{$\begin{array}{c}P P V \text { of new concrete } \\
\text { lining }(\mathrm{cm} / \mathrm{s})\end{array}$} & \multirow[t]{2}{*}{ Distance to blasting source $(\mathrm{m})$} & \multicolumn{3}{|c|}{$\begin{array}{c}P P V \text { of the old } \\
\text { concrete lining }(\mathrm{cm} / \mathrm{s})\end{array}$} \\
\hline & & & $V_{X}$ & $V_{Y}$ & $V_{Z}$ & & $V_{X}$ & $V_{Y}$ & $V_{Z}$ \\
\hline \multirow{2}{*}{1} & \multirow{2}{*}{50.4} & $R_{2}=20.3$ & 7.258 & 6.501 & 6.647 & $R_{3}=29.6$ & 4.572 & 6.875 & 5.006 \\
\hline & & $R_{1}=42.7$ & 2.904 & 2.206 & 1.324 & $R_{4}=110.8$ & 0.197 & 0.280 & 0.384 \\
\hline \multirow{2}{*}{2} & \multirow{2}{*}{27.3} & $R_{2}=19.7$ & 6.465 & 5.535 & 4.943 & $R_{3}=20.0$ & 5.701 & 8.246 & 5.476 \\
\hline & & $R_{1}=52.6$ & 1.346 & 0.640 & 1.674 & $R_{4}=74.2$ & 0.375 & 1.165 & 1.211 \\
\hline \multirow{2}{*}{3} & \multirow{2}{*}{31.2} & $R_{2}=22.7$ & 4.121 & 3.194 & 3.030 & $R_{3}=40.4$ & 3.307 & 3.641 & 2.741 \\
\hline & & $R_{1}=44.0$ & 1.122 & 1.067 & 1.846 & $R_{4}=95.7$ & 0.445 & 1.265 & 0.915 \\
\hline \multirow{2}{*}{4} & \multirow{2}{*}{27.3} & $R_{2}=31.6$ & 2.100 & 2.911 & 2.120 & $R_{3}=50.8$ & 1.865 & 2.273 & 1.978 \\
\hline & & $R_{1}=98.0$ & 0.505 & 0.194 & 0.178 & $R_{4}=70.9$ & 1.996 & 1.997 & 1.044 \\
\hline \multirow{2}{*}{5} & \multirow{2}{*}{31.2} & $R_{2}=48.9$ & 1.474 & 1.826 & 0.807 & $R_{3}=37.2$ & 3.653 & 4.919 & 2.007 \\
\hline & & $R_{1}=109.5$ & 0.170 & 0.170 & 0.242 & $R_{4}=70.8$ & 0.403 & 1.824 & 1.189 \\
\hline \multirow{2}{*}{6} & \multirow{2}{*}{27.3} & $R_{2}=29.9$ & 3.617 & 2.654 & 1.637 & $R_{3}=42.4$ & 1.279 & 2.289 & 1.686 \\
\hline & & $R_{1}=117.2$ & 0.180 & 0.137 & 0.378 & $R_{4}=101.5$ & 0.359 & 0.804 & 0.840 \\
\hline \multirow{2}{*}{7} & \multirow{2}{*}{31.2} & $R_{2}=26.5$ & 4.181 & 2.209 & 3.261 & $R_{3}=55.3$ & 1.666 & 2.851 & 1.798 \\
\hline & & $R_{1}=71.3$ & 0.790 & 0.289 & 0.256 & $R_{4}=135.2$ & 0.406 & 0.488 & 0.703 \\
\hline \multirow{2}{*}{8} & \multirow{2}{*}{27.3} & $R_{2}=36.2$ & 1.272 & 2.167 & 2.122 & $R_{3}=44.8$ & 0.910 & 2.541 & 1.345 \\
\hline & & $R_{1}=79.2$ & 0.649 & 0.292 & 0.323 & $R_{4}=156.6$ & 0.422 & 0.658 & 0.256 \\
\hline \multirow{2}{*}{9} & \multirow{2}{*}{31.2} & $R_{2}=28.4$ & 1.840 & 2.492 & 1.715 & $R_{3}=87.0$ & 0.840 & 0.988 & 1.697 \\
\hline & & $R_{1}=78.6$ & 0.294 & 0.693 & 0.867 & $R_{4}=114.2$ & 0.206 & 0.740 & 0.193 \\
\hline \multirow{2}{*}{10} & \multirow{2}{*}{27.3} & $R_{2}=42.9$ & 1.673 & 2.195 & 0.730 & $R_{3}=98.1$ & 0.686 & 0.216 & 0.363 \\
\hline & & $R_{1}=140.4$ & 0.159 & 0.097 & 0.409 & $R_{4}=120.4$ & 0.545 & 0.452 & 0.938 \\
\hline
\end{tabular}


According to the field test data for the blasting vibrations in Table 1, the variations of the PPV with respect to the proportional distance ([PD]) for the new and old concrete linings were analyzed via regression analysis. Figures 9 and 10 present the variation of the PPV with respect to [PD] for the new concrete lining and the old concrete lining, respectively. As shown, the measured PPVs in the new and old concrete linings of the Yujiaya tunnel decreased with an increase in the proportional distance, indicating that the PPV was higher for a larger TNT weight and lower for a longer distance to the blasting source. Because the surrounding rock structure of the new tunnel differed from that of the old tunnel lining, the incident and reflection modes of the stress wave were different, resulting in significant differences in the PPV between the new and old concrete linings. According to the regression analysis using equations (1) and (2), the corresponding attenuation parameters $K$ and $\alpha$ of stress wave propagation were determined, and then the empirical formula for the attenuation of the PPV in each direction was obtained, as follows (as shown in Figures 9 and 10):

New concrete lining:

$$
\begin{cases}V_{X}=170.15[\mathrm{PD}]^{-1.810}, & R^{2}=0.82, \\ V_{Y}=206.92[\mathrm{PD}]^{-1.965}, & R^{2}=0.79, \\ V_{Z}=68.69[\mathrm{PD}]^{-1.523}, & R^{2}=0.73 .\end{cases}
$$

Old concrete lining:

$$
\begin{cases}V_{X}=124.41[\mathrm{PD}]^{-1.599}, & R^{2}=0.78, \\ V_{Y}=216.59[\mathrm{PD}]^{-1.632}, & R^{2}=0.84, \\ V_{Z}=74.32[\mathrm{PD}]^{-1.359}, & R^{2}=0.70 .\end{cases}
$$

Comparing the fitted curves in Figures 9 and 10 reveals that the $K$ value of the new concrete linings varied between 68 and 206 and that $\alpha$ varied greatly, ranging from 1.523 to 1.965. However, the $K$ value of the old concrete linings varied widely (between 74 and 216), and $\alpha$ varied from 1.359 to 1.623. Therefore, the PPV caused by blasting was attenuated faster in the new concrete lining than in the old concrete lining. In the case of the new concrete lining, when the stress wave encounters a free surface, joint fissure, or fault during the propagation process, it may be reflected and refracted, which can result in energy loss of the stress wave and rapid attenuation of the PPV. Additionally, because the new tunnel excavation forms a circular cutting groove, similar to the artificial damping belt, the blasting stress wave cannot directly act on the primary support structure; rather, it affects the primary support structure through the tunnel floor and the vault diffraction at the monitoring points of the new concrete linings. It was mainly affected by the stress in the $X$ and $Y$ directions; thus, the PPV in the $Z$ direction was lower than that in the other directions for the new concrete linings. Additionally, the correlation coefficients of the fitting curves $\left(R^{2}\right)$ were relatively small, ranging from 0.70 to 0.84 . This is explained as follows: the geological surrounding rock conditions in the tunnel were complex, the blasting

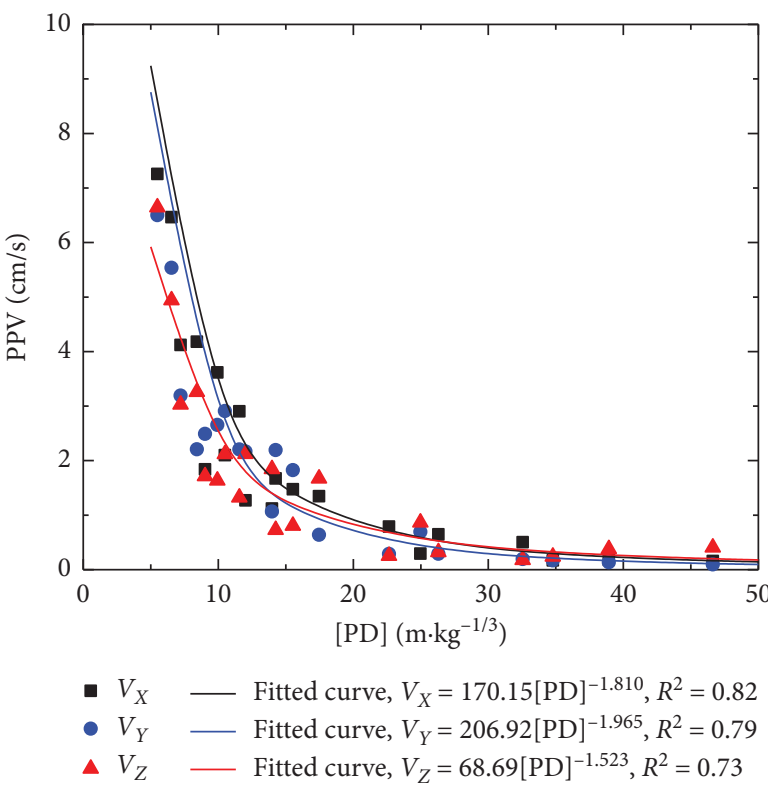

FIGURE 9: Variation of the PPV with respect to [PD] for the new concrete lining.

conditions and environmental factors changed significantly, and the difference between the installation position and the height of the instrument may have led to an error in the measurement of the PPV. However, overall, the attenuation law of the PPV was consistent with Sadovsky's empirical formula.

4.2. Main Vibration Frequency. In many countries, the influence of the main vibration frequency of the blasting stress wave is considered during the formulation of the Blasting Safety Regulations. Previous studies indicated that the main vibration frequency of blasting vibrations affects the damage to buildings and structures [40-42]. The main vibration frequency closer to the natural frequency of the buildings results in greater damage to the buildings. A large amount of data for the main vibration frequency induced by blasting in this case history was collected, as shown in Table 2. Additionally, the distribution of the measured main vibration frequency was analyzed for the new and old concrete linings. As shown in Figures 11 and 12, the measured main vibration frequency was divided into five intervals: $0-30,30-60,60-90,90-120$, and $>120 \mathrm{~Hz}$. The main vibration frequency in this case history was mainly distributed in the range of $0-90 \mathrm{~Hz}$ (approximately $85 \%$ of the data). Figure 13 presents the variation of the main vibration frequency with respect to the distance to the blasting source. As shown, the main vibration frequency measured in the blasting was higher (between 11.72 and $147.45 \mathrm{~Hz}$ ), but with the increasing distance to the blasting source, the main vibration frequency decreased, similar to the investigation results for the frequency variation reported by Singh et al. $[36,43]$. This confirms the accuracy of the test results. Additionally, because the natural frequencies of most ground structures are relatively low, it is more difficult for high-frequency vibration to resonate with adjacent structures, and the vibration does not damage buildings or structures. To quantitatively evaluate the relationship between the main 


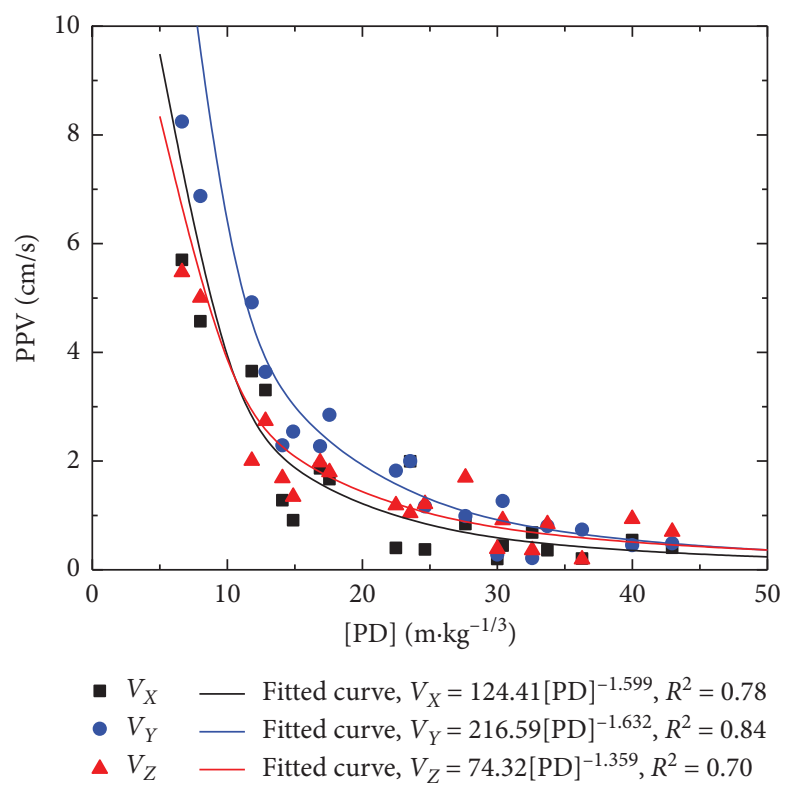

Figure 10: Variation of the PPV with respect to [PD] for the old concrete lining.

TABLE 2: Observed main vibration frequency for the examined case history.

\begin{tabular}{|c|c|c|c|c|c|c|c|c|c|}
\hline \multirow[t]{2}{*}{$\begin{array}{l}\text { Test } \\
\text { number }\end{array}$} & \multirow[t]{2}{*}{$\begin{array}{l}\text { TNT weight } \\
\text { per delay }(\mathrm{kg})\end{array}$} & \multirow[t]{2}{*}{$\begin{array}{c}\text { Distance to } \\
\text { blasting source }(\mathrm{m})\end{array}$} & \multicolumn{3}{|c|}{$\begin{array}{c}\text { Main vibration } \\
\text { frequency of new } \\
\text { concrete lining }(\mathrm{Hz})\end{array}$} & \multirow[t]{2}{*}{ Distance to blasting source $(\mathrm{m})$} & \multicolumn{3}{|c|}{$\begin{array}{c}\text { Main vibration } \\
\text { frequency of old } \\
\text { concrete lining }(\mathrm{Hz})\end{array}$} \\
\hline & & & $F_{\mathrm{X}}$ & $F_{\mathrm{Y}}$ & $F_{Z}$ & & $F_{\mathrm{X}}$ & $F_{\mathrm{Y}}$ & $F_{Z}$ \\
\hline \multirow{2}{*}{1} & \multirow{2}{*}{50.4} & $R_{2}=20.3$ & 45.62 & 117.14 & 89.65 & $R_{3}=29.6$ & 123.25 & 93.95 & 113.28 \\
\hline & & $R_{1}=42.7$ & 40.25 & 23.53 & 18.90 & $R_{4}=110.8$ & 11.72 & 23.43 & 23.45 \\
\hline \multirow{2}{*}{2} & \multirow{2}{*}{27.3} & $R_{2}=19.7$ & 119.61 & 127.97 & 64.52 & $R_{3}=20.0$ & 118.60 & 83.32 & 108.76 \\
\hline & & $R_{1}=52.6$ & 27.35 & 35.87 & 54.60 & $R_{4}=74.2$ & 37.45 & 27.62 & 18.55 \\
\hline \multirow{2}{*}{3} & \multirow{2}{*}{31.2} & $R_{2}=22.7$ & 62.55 & 112.36 & 108.42 & $R_{3}=40.4$ & 28.98 & 127.65 & 105.26 \\
\hline & & $R_{1}=44.0$ & 44.68 & 50.29 & 72.68 & $R_{4}=95.7$ & 22.92 & 69.30 & 20.15 \\
\hline \multirow{2}{*}{4} & \multirow{2}{*}{27.3} & $R_{2}=31.6$ & 75.69 & 67.45 & 25.68 & $R_{3}=50.8$ & 87.82 & 65.05 & 49.60 \\
\hline & & $R_{1}=98.0$ & 35.89 & 20.58 & 26.50 & $R_{4}=70.9$ & 17.87 & 35.65 & 28.37 \\
\hline \multirow{2}{*}{5} & \multirow{2}{*}{31.2} & $R_{2}=48.9$ & 56.67 & 69.85 & 29.62 & $R_{3}=37.2$ & 122.05 & 78.62 & 60.25 \\
\hline & & $R_{1}=109.5$ & 29.68 & 25.46 & 19.60 & $R_{4}=70.8$ & 35.80 & 42.68 & 39.07 \\
\hline \multirow{2}{*}{6} & \multirow{2}{*}{27.3} & $R_{2}=29.9$ & 39.83 & 67.79 & 130.34 & $R_{3}=42.4$ & 55.54 & 65.06 & 46.58 \\
\hline & & $R_{1}=117.2$ & 19.62 & 15.67 & 22.18 & $R_{4}=101.5$ & 22.15 & 32.58 & 28.40 \\
\hline \multirow{2}{*}{7} & \multirow{2}{*}{31.2} & $R_{2}=26.5$ & 127.65 & 86.20 & 147.45 & $R_{3}=55.3$ & 78.52 & 65.43 & 45.09 \\
\hline & & $R_{1}=71.3$ & 38.66 & 42.18 & 19.57 & $R_{4}=135.2$ & 12.56 & 24.11 & 19.50 \\
\hline \multirow{2}{*}{8} & \multirow{2}{*}{27.3} & $R_{2}=36.2$ & 83.34 & 69.22 & 74.05 & $R_{3}=44.8$ & 85.62 & 76.53 & 55.45 \\
\hline & & $R_{1}=79.2$ & 23.80 & 56.49 & 79.52 & $R_{4}=156.6$ & 13.68 & 17.98 & 26.80 \\
\hline \multirow{2}{*}{9} & \multirow{2}{*}{31.2} & $R_{2}=28.4$ & 112.36 & 56.26 & 78.32 & $R_{3}=87.0$ & 25.68 & 102.60 & 39.86 \\
\hline & & $R_{1}=78.6$ & 42.32 & 65.24 & 25.60 & $R_{4}=114.2$ & 25.64 & 22.30 & 32.05 \\
\hline \multirow{2}{*}{10} & \multirow{2}{*}{27.3} & $R_{2}=42.9$ & 57.29 & 61.07 & 87.00 & $R_{3}=98.1$ & 72.58 & 45.62 & 19.82 \\
\hline & & $R_{1}=140.4$ & 17.85 & 24.68 & 20.55 & $R_{4}=120.4$ & 42.26 & 22.80 & 21.09 \\
\hline
\end{tabular}

vibration frequency and the distance to the blasting source, a regression analysis of the observed data was performed, which indicated that a power function $\left(y=2018 x^{-0.93}, R^{2}=0.77\right)$ may be reasonable, as shown in Figure 13.

4.3. Discussion on Safety Distance of Concrete Linings. In this study, the PPVs at different distances from the blasting source were determined via the field test. However, the PPVs close to the blasting source could not be monitored, owing to safety considerations. Therefore, the PPVs at different distances from the blasting source were calculated using equation (4). Figure 14 presents the variation of the PPV in different directions with respect to the distance from the blasting source for the concrete lining. The PPV curve is based on equation (4). As shown, for the TNT weight of 


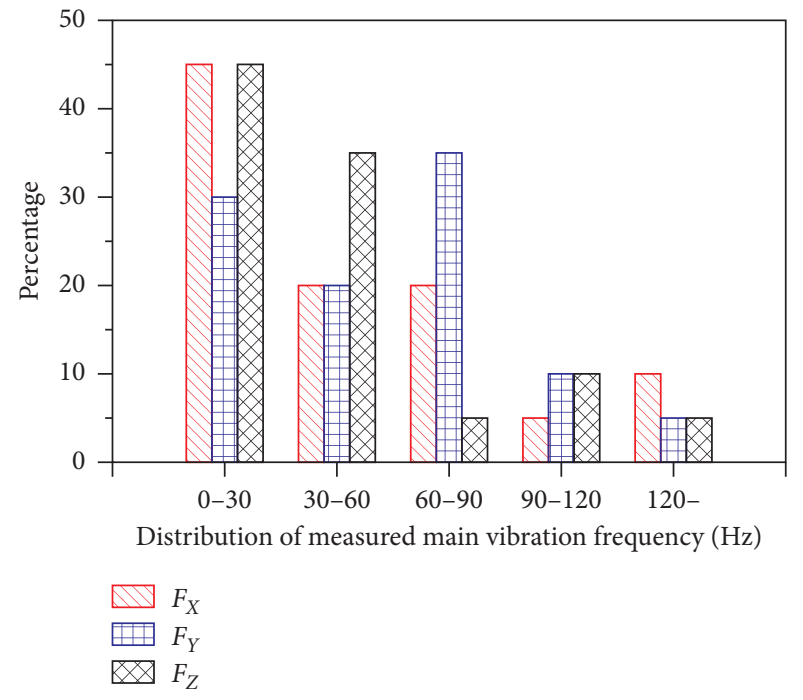

FIGURE 11: Distribution of the measured main vibration frequency for the old concrete lining.

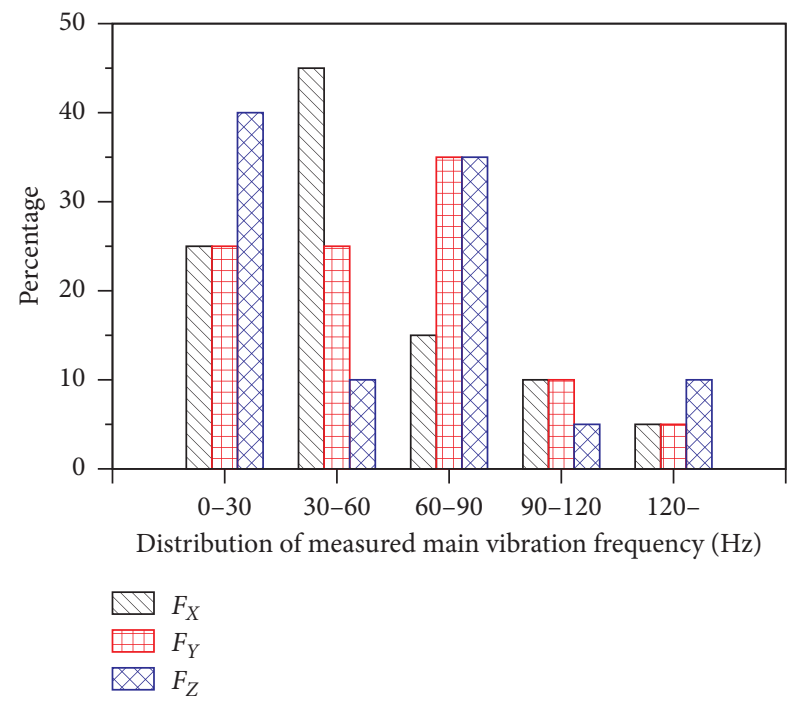

FIGURE 12: Distribution of the measured main vibration frequency for the new concrete lining.

$Q_{\max }=50.4 \mathrm{~kg}$, if the $\mathrm{PPV}$ is $>20 \mathrm{~cm} / \mathrm{s}$, damage may be induced to the concrete lining, and the safety distance for the case of $10 \leq V_{X} \leq 20 \mathrm{~cm} / \mathrm{s}$ is $16-24 \mathrm{~m}$. The safety distances for the cases of $10 \leq V_{Y} \leq 20 \mathrm{~cm} / \mathrm{s}$ and $10 \leq V_{Z} \leq 20 \mathrm{~cm} / \mathrm{s}$ are 12-18 and $10-17 \mathrm{~m}$, respectively. The obtained safety distances are valuable references for similar tunnel construction projects.

\section{Conclusions}

At present, several old mountain highway tunnels in China need to be rebuilt or expanded because of the declining health of concrete linings and the growing traffic demands. It is important to monitor the vibrations caused by blasting to avoid the continuous collapse of the old concrete lining during the expansion of old mountain highway tunnels. In

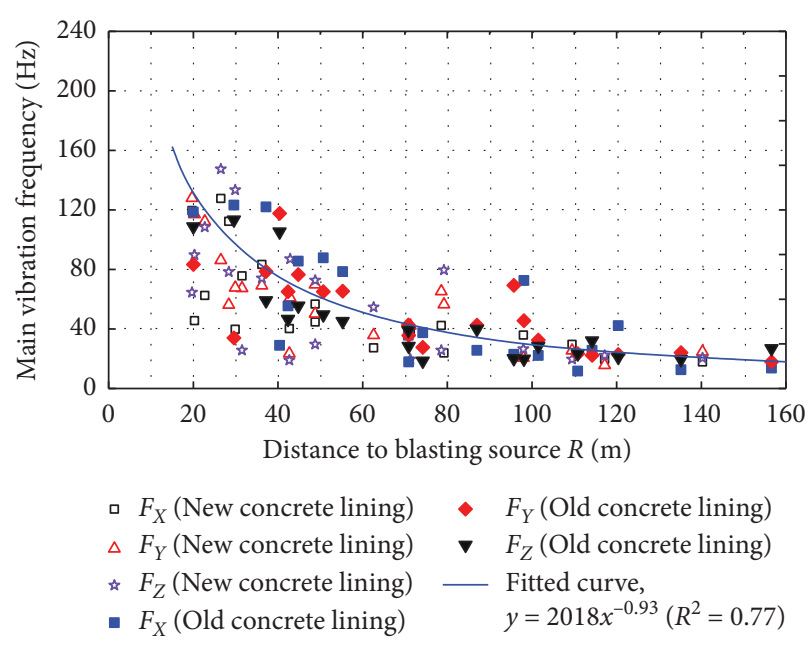

FIGURE 13: Variation of the main vibration frequency with respect to the distance to the blasting source.

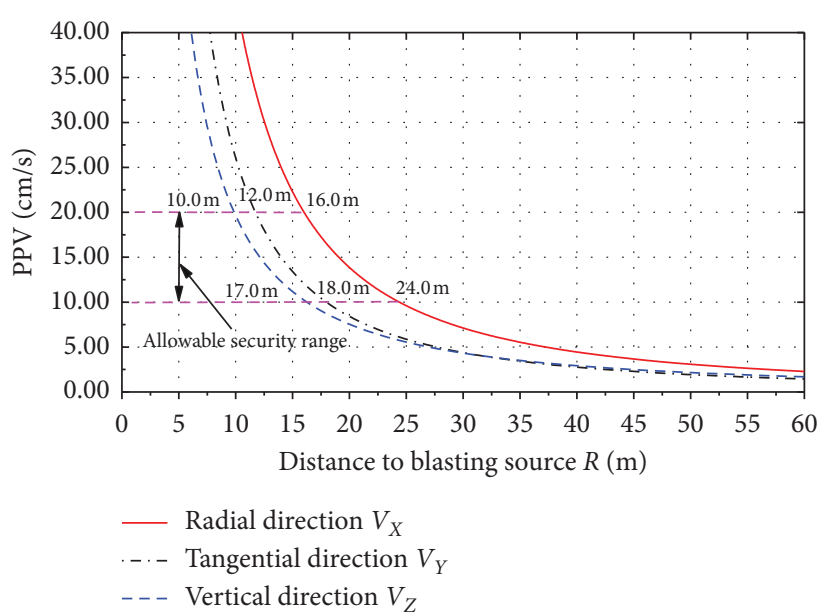

FIGURe 14: Variation of the PPV with respect to the distance from the blasting source for the concrete lining.

this study, a case history of the expansion of the Yujiaya tunnel, located in Shaanxi Province and constructed in 1999, was analyzed. During the expansion process, the blastinginduced vibrations in the new and old concrete linings were monitored. The results indicated that the measured values of the PPV varied within the range of $0.097-8.246 \mathrm{~cm} / \mathrm{s}$. By performing a regression analysis with Sadovsky's empirical formula, the attenuation law of the PPV was determined. A power function was established to quantitatively evaluate the relationship between the main vibration frequency and the distance to the blasting source. The results indicated that the safety distance of concrete linings for the case of $10 \leq V_{X} \leq 20 \mathrm{~cm} / \mathrm{s}$ is $16-24 \mathrm{~m}$, and the safety distances for the two cases of $10 \leq V_{Y} \leq 20 \mathrm{~cm} / \mathrm{s}$ and $10 \leq V_{Z} \leq 20 \mathrm{~cm} / \mathrm{s}$ are 12-18 and $10-17 \mathrm{~m}$, respectively.

\section{Data Availability}

The data used to support the findings of this research work are included within the article. 


\section{Conflicts of Interest}

The authors declare no conflicts of interest.

\section{Acknowledgments}

This work was funded by the National Key R\&D Program of China (Grant no. 2017YFC0805306), the project supported by the Natural Science Basic Research Plan in Shaanxi Province of China (Grant no. 2019JQ-114), the National Nature Science Foundation of China (NSFC) (Grant nos. 41702287 and 51978059), and the Fundamental Research Funds for the Central Universities (Grant no. 300102218517). The financial support received is gratefully acknowledged.

\section{References}

[1] W. C. Cheng, J. C. Ni, and S. L. Shen, "Experimental and analytical modeling of shield segment under cyclic loading," International Journal of Geomechanics, vol. 17, no. 6, Article ID 04016146, 2016.

[2] W.-C. Cheng, G. Li, N. Liu, J. Xu, and S. Horpibulsuk, "Recent massive incidents for subway construction in soft alluvial deposits of Taiwan: a review," Tunnelling and Underground Space Technology, vol. 96, Article ID 103178, 2020.

[3] J. Lai, X. Wang, J. Qiu et al., "A state-of-the-art review of sustainable energy based freeze proof technology for coldregion tunnels in China," Renewable and Sustainable Energy Reviews, vol. 82, no. 3, pp. 3554-3569, 2018.

[4] Y.-Q. Wang, Z.-F. Wang, and W.-C. Cheng, "A review on land subsidence caused by groundwater withdrawal in Xi'an, China," Bulletin of Engineering Geology and the Environment, vol. 78, no. 4, pp. 2851-2863, 2019a.

[5] Z.-F. Wang, S.-L. Shen, and G. Modoni, "Enhancing discharge of spoil to mitigate disturbance induced by horizontal jet grouting in clayey soil: theoretical model and application," Computers and Geotechnics, vol. 111, pp. 222-228, $2019 \mathrm{~b}$.

[6] Y.-q. Wang, S. Xu, R. Ren, S. Zhang, and Z. Ren, "Application of the twin-tube complementary ventilation system in largeslopping road tunnels in China," International Journal of Ventilation, vol. 19, no. 1, pp. 63-82, 2020a.

[7] P. Li, Y. Zhao, and X. Zhou, "Displacement characteristics of high-speed railway tunnel construction in loess ground by using multi-step excavation method," Tunnelling and Underground Space Technology, vol. 51, pp. 41-55, 2016.

[8] S. Lu, C. Zhou, N. Jiang, and X. Xu, "Effect of excavation blasting in an under-cross tunnel on airport runway," Geotechnical and Geological Engineering, vol. 33, no. 4, pp. 973981, 2015.

[9] R. Ren, S. Xu, Z. Ren et al., "Numerical investigation of particle concentration distribution characteristics in twintunnel complementary ventilation system," Mathematical Problems in Engineering, vol. 2018, Article ID 1329187, 13 pages, 2018.

[10] W.-C. Cheng, J. C. Ni, H.-W. Huang, J. S. Shen, and J. S. Shen, "The use of tunnelling parameters and spoil characteristics to assess soil types: a case study from alluvial deposits at a pipejacking project site," Bulletin of Engineering Geology and the Environment, vol. 78, no. 4, pp. 2933-2942, 2019a.

[11] P. Li and Y. Zhao, "Performance of a multi-face tunnel excavated in loess ground based on field monitoring and numerical modeling," Arabian Journal of Geosciences, vol. 9, no. 14, 640 pages, 2016.

[12] J. Qiu, H. Liu, J. Lai, H. Lai, J. Chen, and K. Wang, "Investigating the long-term settlement of a tunnel built over improved loessial foundation soil using jet grouting technique," Journal of Performance of Constructed Facilities, vol. 32, no. 5, Article ID 04018066, 2018.

[13] J. Qiu, Y. Xie, H. Fan, Z. Wang, and Y. Zhang, "Centrifuge modelling of twin-tunnelling induced ground movements in loess strata," Arabian Journal of Geosciences, vol. 10, no. 22, 493 pages, 2017.

[14] V. R. Feldgun, A. V. Kochetkov, Y. S. Karinski, and D. Z. Yankelevsky, "Internal blast loading in a buried lined tunnel," International Journal of Impact Engineering, vol. 35, no. 3, pp. 172-183, 2008.

[15] W. He, J.-y. Chen, and J. Guo, "Dynamic analysis of subway station subjected to internal blast loading," Journal of Central South University, vol. 18, no. 3, pp. 917-924, 2011.

[16] N. Jiang and C. Zhou, "Blasting vibration safety criterion for a tunnel liner structure," Tunnelling and Underground Space Technology, vol. 32, pp. 52-57, 2012.

[17] H. Liu, "Dynamic analysis of subway structures under blast loading," Geotechnical and Geological Engineering, vol. 27, no. 6, p. 699, 2009.

[18] Z.-F. Wang, S.-L. Shen, G. Modoni, and A. Zhou, "Excess pore water pressure caused by the installation of jet grouting columns in clay," Computers and Geotechnics, vol. 125, Article ID 103667, 2020b.

[19] W.-C. Cheng, J. C. Ni, A. Arulrajah, and H.-W. Huang, "A simple approach for characterising tunnel bore conditions based upon pipe-jacking data," Tunnelling and Underground Space Technology, vol. 71, pp. 494-504, 2018.

[20] Y. Wei, X. Gao, and S. Liang, "A combined SPM/NI/EDS method to quantify properties of inner and outer C-S-H in OPC and slag-blended cement pastes," Cement and Concrete Composites, vol. 85, pp. 56-66, 2018.

[21] Y. Wei, X. Gao, F. Wang, and Y. Zhong, "Nonlinear strain distribution in a field-instrumented concrete pavement slab in response to environmental effects," Road Materials and Pavement Design, vol. 20, no. 2, pp. 367-380, 2019.

[22] Y. Wei, S. Liang, W. Guo, and W. Hansen, "Stress prediction in very early-age concrete subject to restraint under varying temperature histories," Cement and Concrete Composites, vol. 83, pp. 45-56, 2017.

[23] M. Chen, W. B. Lu, P. Yan, and Y. G. Hu, "Blasting excavation induced damage of surrounding rock masses in deep-buried tunnels," KSCE Journal of Civil Engineering, vol. 20, no. 2, pp. 933-942, 2016.

[24] W.-C. Cheng, L. Wang, Z.-F. Xue, J. C. Ni, M. M. Rahman, and A. Arulrajah, "Lubrication performance of pipejacking in soft alluvial deposits," Tunnelling and Underground Space Technology, vol. 91, p. 102991, 2019 b.

[25] R. Kumar, D. Choudhury, and K. Bhargava, "Determination of blast-induced ground vibration equations for rocks using mechanical and geological properties," Journal of Rock Mechanics and Geotechnical Engineering, vol. 8, no. 3, pp. 341349, 2016.

[26] K.-I. Song, T.-M. Oh, and G.-C. Cho, "Precutting of tunnel perimeter for reducing blasting-induced vibration and damaged zone - numerical analysis," KSCE Journal of Civil Engineering, vol. 18, no. 4, pp. 1165-1175, 2014.

[27] L. Ahmed and A. Ansell, "Structural dynamic and stress wave models for the analysis of shotcrete on rock exposed to blasting," Engineering structures, vol. 35, pp. 11-17, 2012. 
[28] L. Ahmed and A. Ansell, "Vibration vulnerability of shotcrete on tunnel walls during construction blasting," Tunnelling and Underground Space Technology, vol. 42, pp. 105-111, 2014.

[29] M. Monjezi, M. Ghafurikalajahi, and A. Bahrami, "Prediction of blast-induced ground vibration using artificial neural networks," Tunnelling and Underground Space Technology, vol. 26, no. 1, pp. 46-50, 2011.

[30] Q. M. Xie, Y. Y. Xia, and X. P. Li, "Study on blasting vibration control of creep mass slope of longtan hydropower station," Journal of Rock Mechanics and Engineering, vol. 22, no. 11, pp. 1929-1932, 2003, in Chinese.

[31] H. Yu, Y. Yuan, G. Yu, and X. Liu, "Evaluation of influence of vibrations generated by blasting construction on an existing tunnel in soft soils," Tunnelling and Underground Space Technology, vol. 43, pp. 59-66, 2014.

[32] J. S. Lee, S. K. Ahn, and M. Sagong, "Attenuation of blast vibration in tunneling using a pre-cut discontinuity," Tunnelling and Underground Space Technology, vol. 52, pp. 30-37, 2016.

[33] A. Parida and M. K. Mishra, "Blast vibration analysis by different predictor approaches-a comparison," Procedia Earth and Planetary Science, vol. 11, pp. 337-345, 2015.

[34] Z.-F. Wang, J. S. Shen, and W.-C. Cheng, "Simple method to predict ground displacements caused by installing horizontal jet-grouting columns," Mathematical Problems in Engineering, vol. 2018, Article ID 1897394, 11 pages, 2018a.

[35] Z.-F. Wang, W.-C. Cheng, and Y.-Q. Wang, "Investigation into geohazards during urbanization process of Xi'an, China," Natural Hazards, vol. 92, no. 3, pp. 1937-1953, 2018b.

[36] J. H. Yang, W. B. Lu, Q. H. Jiang, C. Yao, and C. B. Zhou, "Frequency comparison of blast-induced vibration per delay for the full-face millisecond delay blasting in underground opening excavation," Tunnelling and Underground Space Technology, vol. 51, pp. 189-201, 2016.

[37] J. Lai, H. Fan, J. Chen, J. Qiu, and K. Wang, "Blasting vibration monitoring of undercrossing railway tunnel using wireless sensor network," International Journal of Distributed Sensor Networks, vol. 11, no. 6, Article ID 703980, 2015.

[38] J. H. Yang, W. B. Lu, Z. G. Zhao, P. Yan, and M. Chen, "Safety distance for secondary shotcrete subjected to blasting vibration in jinping-II deep-buried tunnels," Tunnelling and Underground Space Technology, vol. 43, pp. 123-132, 2014.

[39] SRFB, Safety Regulations for Blasting: National Standards Editorial Committee of the People's Republic of China, China Standards Press, Beijing, China, 2014, in Chinese.

[40] X.M. Guan, X.C. Wang, Z. Zhu, L. Zhang, and H.X. Fu, "Ground vibration test and dynamic response of horseshoeshaped pipeline during tunnel blasting excavation in pebbly sandy soil," Geotechnical and Geological Engineering, vol. 38, pp. 3725-3736, 2020.

[41] X. Guan, C. Zhang, F. Zhao, B. Mou, and Y. Ge, "Stress response and damage characteristics of local members of a structure due to tunnel blasting vibrations based on the highorder local modal analysis," Shock and Vibration, vol. 2019, Article ID 7075024, 18 pages, 2019.

[42] C. Shi, Q. Zhao, M. Lei, and M. Peng, "Vibration velocity control standard of buried pipeline under blast loading of adjacent tunnel," Soils and Foundations, vol. 59, no. 6, pp. 2195-2205, 2019.

[43] P. K. Singh, M. P. Roy, R. K. Paswan, R. K. Dubey, and C. Drebenstedt, "Blast vibration effects in an underground mine caused by open-pit mining," International Journal of Rock Mechanics and Mining Sciences, vol. 80, pp. 79-88, 2015. 